\title{
Retraction: A handy way to handle hemoclips $₫$ in surgeries
}

Shunjie Chua, Mark Pitts, Peter Lemark, Min Le

Singapore Med J 2015; 56(12): 695; https://doi.org/10.11622/smedj.2015191

Following investigation of allegations of professional misconduct, the Singapore Medical Council (SMC) has confirmed that the corresponding author, Chua SJ, had provided fictitious names as co-authors of this paper.

In view of the misrepresentation of authorship claims, the Singapore Medical Journal fully retracts this paper from its published record.

Poh Kian Keong

Editor-in-Chief

Singapore Medical Journal

https://doi.org/10.11622/smedj.2020135 